thing as 'environmental control'; and it is, therefore, particularly appropriate that geographers should concern themselves with tropical regions. Increasingly it is being recognized that the economic development of the tropics cannot come about except by the conquest of disease, the raising of standards of living, and the institution of comprehensive programmes of drainage and irrigation, road-building and port development. The blind belief in the inherent fertility of the tropies has at long last disappeared : and projects like the groundnut scheme in East Africa can succeed only after the most careful study of the facts of geology and topography, temperature and rainfall, natural vegetation and soil types. These facts are rightly studied by specialists-by geologists, meteorologists, plant ecologists, soil scientists, and the like. Too often, though, the interactions of these facts are inadequately considered, since they lie in the province of no particular specialist: and it is here that the geographer believes that he has a place in the scientific hierarchy, since by the nature of his training he is specially equipped to look out for interconnexions. $\mathrm{He}$ is not content with the facts of either geology or meteorology or botany, taken by themselves, in any particular area. He wants the complete picture-made up of physical conditions and human responses-or, as he puts it, the 'regional geography'.

The work of many of the economic and other missions to British Colonies in recent years would have been greatly facilitated if less time could have been spent in fact-finding, and more attention paid to the elaboration of concrete development programmes. Had the regional geography of British Colonies been studied as fully as that of, say, France -or even as inadequately as that of Great Britain itself-these missions would have had at least a basis on which to build. As it is, the regional geography of the Colonial Empire remains unwritten, apart from the isolated work of pioneers such as Clement Gillman in Tanganyika Territory. In this connexion the new colonial universities and colleges have an important contribution to make to our geographical knowledge of the world.

More than one speaker stressed the need for a colonial atlas, in the preparation of which geographers would take a prominent role: such an atlas would include distribution as well as topographical maps. The French and Dutch colonial atlases were quoted as excellent examples, and reference made to the successful efforts of Section $\mathbf{E}$ of the British Association in pushing forward the preparation of a National Atlas for Great Britain. It was suggested that as a first stage, maps might be prepared for groups of British territories, full use being made of the technique of mapping from air photographs and of the resources of the Directorate of Colonial Surveys.

Lord Rennell concluded by stating that facilities are now available for geographers to an extent nevier known before, and that the Colonial Office has recently asked specifically for trained geographers for research investigations in the Colonies. It is now open to geographers to make as effective a contribu. tion to the study of the problems of colonial development as they have made at home, through the Land Utilisation Survey and in other ways, to the problems of agriculture and of town and country planning. Their fellow-scientists will judge the validity of the geographers' claim by the quality of their work in the colonial field and by the distinetiveness of their contribution.

\section{NATURE OF INCENTIVES}

A S might have been expected, the discussion of A 'incentives' in the meeting at Brighton of Section J (Psychology) of the British Association afforded yet another opportunity for attempting to define the nature and extent of the responsibility of scientific workers for industrial efficiency. From various points of view, industry was challenged to try out new techniques and policies of management, and men of science were challenged to develop new concepts and procedures in the organisation of research.

Mr. Nigel Balchin, who opened the symposium, expanded his now well-known thesis that under present social conditions the traditional incentive of financial rewards has broken down, and that in future industry must rely upon entirely different motives for the maintenance of optimum effort. "If we have," he said, "on one hand a perfectly reasonable demand for a high material standard of life, which can only be supplied by productive effort, and on the other an equally reasonable demand for happiness in astivity, the only possible solution is to make work the happy activity." Since we do not yet know how this is to be done, the first responsibility of the man of science is to engage in research into basic principles. Psychologists should stop "trying to run other peoples factories' and concentrate on research into general principles.

The main themes of the second paper (that of the present writer) were in more than one way complementary to those of Mr. Balchin. There is, of course, much that we do not know; but, it was argued, there is also much that we know well enough but do not act upon. Research in this field, the results of which would be applicable, cannot be conducted entirely outside the factory but depends on close collaboration between scientific workers with more than a superficial knowledge of industrial administra. tion and managers with more than a superficial knowledge of scientific method. One field in which such collaboration would be especially fruitful, both in the application of existing knowledge and in the promotion of fresh research, is that of 'target setting' both on a national seale and in the detailed procedures of time and method study. Evidence of the ripeness of this particular harvest could be adduced from recent trends of thought in scientifically minded exponents of time-study procedures and from the increasingly open-minded and experimental mood of industry itself in this regard. Target, the monthly bulletin of production publicity of the Central Office of Information, is full of reports of new incentive experiments, the results of which should be well worth scientific observation and assessment.

Following up a point first made by Mr. Alec Rodger in the conference at Leamington of the Division for the Social and International Relations of Science of the British Association, it was further suggested that among the preconditions of the effective application of existing technical knowledge is the application of existing knowledge of another kind-of principles governing human relations in industry, on which there is a surprising unanimity of opinion among moral philosophers, political reformers and religious teachers of every school, party and sect. For example, the often quoted precept of Immanuel Kant that "every man should be treated as an end and not merely as a means" is one that in principle admits of translation into scientific terms and into 
terms of industrial practice. So translated, it might be worth submitting to tests acceptable to the statistician and methodologist as theoretically sound, and acceptable to management as workable in practice.

An even more fundamental challenge to science and management would seem to have been implied by the argument of the third contributor to the symposium. According to Mr. Adam Curle, who approached the subject from the point of view of an anthropologist, the very existence of an incentives problem is symptomatic of a malady in modern society. In primitive societies necessary work is as automatic as eating or sex ; and our present problem is nothing less than that of recreating these conditions. This, of course, is not to be achieved by a mere regression to the original order. The need is for a new social order "in which the anxious tensions resulting in withdrawal and isolation from the group can be reduced". We need to provide the conditions of a 'psychological' as well as those of a constitutional democracy. Then the incentives problem would again disappear. Nothing very specific was suggested as to the way in which this might be done; but it would depend on close collaboration between social scientists of many different kinds. The results obtained in army resettlement units, it was suggested, gives some indication of the lines along which to work.

Mr. Alec Rodger, through what at first appeared to be an excursion into lexicography, raised an issue of the greatest moment. The term 'incentive', he pointed out, is commonly used by industrialists and defined in dictionaries by reference to incitements that are essentially passing rather than permanent in effect. On the other hand, the preceding speakers had appeared to be almost exclusively concerned with the conditions that continuously maintain an optimum level of effort throughout the working weeks and years. "Admittedly we need long-term programmes for the improvement of morale, for in the long run this is the only manner in which high industrial productivity is likely to be properly established and sustained; but in our present plight we cannot disdain to use any device which shows promise of yielding quick results." An example of the sort of research which was needed was quoted from some studies of the Social Survey which had given indications that different types of motivation operate at different intelligence levels.

Speaking with intimate and first-hand experience, Mr. Rodger had things to say on the functions of the psychologist in relation to management and administration. The root of the problem, he suggested, lies in the fact that the technical adviser will often miss the opportunity both to understand the principles on which his colleagues work and of dealing with critical situations unless at the decisive moment he is prepared to do the job himself, since he can act with insight and confidence when they cannot.

The discussion as a whole, however inconclusive and however limited in suggestions likely to yield 'quick results' it may have seemed, served a useful purpose in revealing something of the total dimensions of the problem. There is clearly, and by general agreement, a need for expansion and intensification of research and development in which a due balance is preserved between the advance of knowledge and the application of what is already known. There is need for advances both in fundamental research and in the development of practical techniques. It is probably through the development of managerial techniques for using what is already known that the 'quick results' are most likely to be obtained. But it is here, more than anywhere else, that Mr. Rodger's distinction needs to be kept in mind. There is a widespread view among industrial psychologists that the benefits derived from temporary incitements are often paid for dearly through their subsequent effects in fatigue and reaction. If they be correct in this opinion, the use of such expedients can be defended only in an emergency the passing nature of which can be predicted with some assurance. Here, as elsewhere, the best results are likely to be achieved by those who combine a sense of the need for quick results with the wider and the longer view. Perhaps this combination is not to be found in any single scientific or managerial group; and the need will only be met by the kinds of collaboration concerning which all the speakers were agreed. It is accordingly somewhat sobering to reflect that in spite of the widespread interest in the problem, the number of workers actually engaged in relevant research at this time is extremely small.

C. A. MACE

\section{TRANSMISSION OF EFFECTS FROM THE ENDINGS OF NERVE FIBRES}

\section{DISCUSSION on the transmission of effects} A from the ends of nerve fibres occupied an afternoon session of Section I (Physiology) of the British Association on September 9. Sir Henry Dale introduced the discussion by saying that we may agree on the assumption that the liberation of one or another chemical substance with a specific stimulating action is the means by which, in vertebrates, nerve impulses are transmitted from the endings of all efferent fibres of the peripheral nervous system, whether pre- or post-ganglionic fibres of the involuntary nerves, or motor fibres of the voluntary nerves. But there remains a wealth of problems still open to discussion concerning details of such a process.

Since two of the speakers were dealing with the extension of this theory to the vast complex of synaptic junctions in the central nervous system, Sir Henry Dale first discussed this problem. The exciting possibilities presented by studies in this field, he said, have acted as both a stimulus and a deterrent. When, more than twenty years ago, he told Sir Charles Sherrington, then already in retirement, about the evidence that had been obtained at that time in his laboratory for the transmitter function of acetylcholine at preganglionic and voluntary motor nerve endings, Sir Charles' immediate reaction was to insist that a process observed at peripheral synapses must furnish some kind of analogy for events at those of the central nervous system. Referring to the experimental attempt of Dr. W. Feldberg to distinguish central synapses at which transmission may be cholinergic from others at which it is not, Sir Henry Dale said that such a differentiation raises the question as to what the transmitter may be at these others. For it is difficult to suppose that synapses in the central nervous system can differ among themselves so fundamentally in function that transmission at some should be cholinergic and at others involve no kind of chemical agent. Referring to the experiments of Mr. J. W. S. Pringle and Mr. G. M. Hughes, by which the discussion is extended to the nerve ganglia of the ventral chain in an insect, he again pointed out 